\title{
Implementation of game methods in the preparation of management personnel
}

\section{Vinichenko, Mikhail V.; Melnichuk, Alexander V. and Makushkin, Sergey A.}

Department of Personnel Management and Personnel Policy, Russian State Social University, Russia.

\begin{abstract}
The search for increasing the effectiveness of training leads to the use of innovative technologies, which include gaming. The purpose of this article was to identify the extent and nature of the introduction of gaming methods in the educational process of the Russian State Social University. The paper used a comparative analysis of students and teachers assessment of management training using the gaming of the educational process. The empirical basis was the results of a sociological survey conducted using the Google Forms online service. 48 teachers and 178 students took part in the sociological survey. As a result, it was possible to establish that the introduction of gaming in the university is controversial. Despite the understanding of the usefulness of gaming by university employees, only $29 \%$ of teachers constantly use gaming methods. Students are dissatisfied with this, noting that gaming techniques are either fragmented (54\%) or not used at all (37\%). Students with a desire to participate in classes with gaming methods, especially in an integrated business game. Achievement of students' success at the class increases their social status. The study showed that the potential for gaming is not fully used.
\end{abstract}

Keywords: Gaming methods; efficiency; educational process; motivation. 


\section{Introduction}

In the last decade, the dynamics of the development of society is increasingly growing. This affects all sectors of the economy and education, including. At school with students, gaming technologies are increasingly being used in accordance with the age of schoolchildren. Teachers, taking into account the peculiarities of child psychology, effectively and fairly professionally apply gaming methods in the course of training. The situation is somewhat different in the sphere of higher education. Students of the Y and Z generation, who have grown up on the wide application of computer games, social networks (Zdravkova, 2016), technologies and innovative models in all spheres of life (Landers \& Armstrong, 2017) come to universities. The pedagogical staff, especially the scientists of the older generation (generation X), often build their training courses, relying on the classical forms of conducting classes, and rarely using gaming methods. As a result, there is a contradiction between the need for students to obtain information, professional knowledge, competencies in the form in which they are accustomed, which is more accessible and better absorbed and the ability, the desire of the faculty to gamble the learning process.

The problem of gaming is the concern of theoreticians and practitioners around the world. This refers to business, government structures, representatives of the education sector (Alvarez et al, 2017, Miguel et al, 2017, Rogach et al, 2017). Age and gender specificities of gaming are studied (Marti-Parreno et al, 2016), security and confidentiality (Baxter et al, 2016), cognitive learning (Lumsden et al, 2016). Game methods are considered when forming a youth policy (Vinichenko et al, 2017).

The main result of the study of Spanish scientists at the University of Valencia was that the use of Information and Communication Technologies (ICT) and classroom gaming in the classroom improved the motivation and training of students, especially those who were less motivated (Serrano and Fajardo, 2017). American scientists for this offer to use regular online assignments (Moore \& Pearson, 2017). Another group of researchers suggests using game methods in making managerial decisions (Wittenbaum et al, 2004).

As the study of the Spanish scientists Polytechnic University of Valencia shows, the use of smartphones in physics training has generated satisfaction and interest among students (Sans et al., 2015).

Using the Dutch experience of gaming training of students with the help of the business game Logistic Support Game (LSG), it was possible to enhance the joint activity of trainees with the distribution of roles for the development of competencies, interaction and autonomy (Martinetti et al., 2017). 
German scientists proposed the integration of gaming management systems and training to create gaming techniques (Bartel et al., 2017). Russian researchers have revealed the advisability of using gaming techniques in developing a reserve pool (Kirillov, et al., 2017).

In general, the use of gaming methods increases the effectiveness of education.

\section{Methodology}

To improve the effectiveness of training managers in the Russian State Social University (RSSU) was chosen course for the gaming of the educational process. In January 2016, a program was developed in which the gaming process was divided into three phases, identifying at the end of each stage the nature and extent of the introduction of gaming methods into the educational process. The first stage of 2016-2017, the second phase of 2018-2019, the third phase of 2020-2021.

The first stage began with the study of the Russian and international experience of gaming training. May 18, 2016, the Moscow Scientific and Practical Conference was held: "Geomification: business and society", which examined and summarized the latest achievements in gaming and defined the tasks for the application of gaming methods in the training of management personnel. The whole faculty of the Russian State Social University was involved in the process of gaming. Each teacher developed and applied his own version of gaming methods in conducting lectures and practical exercises. The main organizer of gaming was the faculty of management. Representatives of the business partners of the ANCOR personnel holding and the group of companies HeadHunter were involved in the management system to transfer experience of gaming. They conducted master classes and demonstrated in practice gaming methods of teaching.

In the interest of assessing the effectiveness of work at the first stage, a methodology was developed to identify the extent and nature of the introduction of gaming methods in the process of training managerial staff and the satisfaction of students and teachers with the gaming of the educational process. Complexly applied methods of typological, historicalgenetic, comparative analysis. The empirical basis was the results of a sociological survey conducted among students and teachers of the Russian State Social University in January 2018. The survey was conducted using the Google Forms online service. The collected data were processed using mathematical statistics. Then, a comparative analysis of the assessment of students 'and teachers' training of managerial personnel on specified indicators was made based on the gaming of the educational process. 48 teachers and 178 students took part in the sociological survey. 
The aim of the study was to identify the extent and nature of the introduction of gaming methods in the educational process through the assessment (satisfaction) of students and teachers of the gaming process in the university.

\section{Results}

The importance of gaming technology for obtaining knowledge and professional competencies was noted by $37.5 \%$ of teachers, $27 \%$ were of secondary importance and $15 \%$ were not singled out among other technologies. The opinions of students on this issue generally coincided with the assessment of teachers. The importance of gaming technology is also put on the first place - $43 \%$ of students, a secondary role was noted by $29 \%$ and $13.5 \%$ of students named equal in relation to other technologies in the matter of obtaining professional competencies.

Constraints to the introduction of gaming technology for teachers are a large amount of time to prepare for the lesson (52\%), a large training load (46\%) and lack of motivation for the teacher to conduct classes with elements of the game $(23 \%)$.

A special place was occupied by the answers to the question: "How often are gaming technologies used during the lesson?" Most teachers sometimes use gaming technology $(62.5 \%)$. Only $29 \%$ of teachers use gaming technology on a continuous basis. This is dissatisfied with the students. 54\% of respondents noted that only gaming techniques were used fragmentarily, and $37 \%$ of students were disappointed that the classes were generally conducted without the use of gaming technologies.

$21 \%$ of teachers believe that the achievements (successes) received by students in classes using gaming methods increase the social status of students; $37.5 \%$ noted the indirect nature of such influence, and $21 \%$ of respondents expressed the opinion that they do not influence the social status of students at all. The students themselves gave more votes in favor of indirect influence $(41 \%)$ and increasing their social status from success in gaming sessions (30\%). $11 \%$ of students noted that such activities have no effect on their social status or have little effect.

Almost half of the teachers believe that practical training with the elements of the game is the most interesting for students (46\%). On the second place were lectures with the game methodology (25\%). Students were also more interested in practical exercises with elements of the game (54\%) and lecture classes with gaming techniques (21\%).

The assessment of the technologies used by teachers and students did not coincide. Teachers often use case studies (71\%), brainstorming (59\%) and complex business games 
$(48 \%)$ most often in class. Students would like to see complex business games (62\%), case studies (45.5\%) and brainstorming (42\%).

\section{Discussion}

The importance of the influence of gaming technology on the quality of obtaining knowledge and professional competencies was highly appreciated by $37.5 \%$ of teachers and $43 \%$ of students. The rest of the teachers give them or a secondary role or do not give them any significant significance at all. This indicates a weak awareness of teachers about the possibilities of such forms of conducting classes, little experience in the use of gaming methods, low motivation and the lack of a desire for continuous development of pedagogical skills.

The nature of the impact of achievements (successes) in games with gaming technology on social status was higher by students $(30 \%)$, (teachers - $21 \%$ ). Students really felt the growth of their authority after a successful performance in such occupations. This should be used by teachers and more actively use this resource to improve the quality of classes. The effect of the "winner" in the classes and after their graduation is sometimes not clear, but a prolonged nature.

The greatest interest among teachers and students is caused by employment with the use of gaming technologies, and priority is given to practical exercises using gaming techniques. In these classes, students are most deeply involved in the process of obtaining knowledge, and the competences obtained are firmly and easily accessible.

The opinion of students and teachers on the frequency of the use of gaming methods did not coincide. Teachers believe that they pay much attention to the use of gaming technology in the classroom - 29\% - constantly, 63\% sometimes they use it and 5\% never. Students have confirmed only that gaming methods are sometimes used by teachers (54\%). Only $4 \%$ of students agree that gaming technology is often used in the classroom and $36.5 \%$ of students said that they have never been used. This suggests that not all gaming technologies are perceived by students as such. The understanding of gaming technology among teachers and students is different. The differences in the vision of this process for the generation $\mathrm{X}$ and for the youths of the $\mathrm{Y}$ and $\mathrm{Z}$ generations are affected. In this regard, it is advisable for teachers to more deeply study the needs and forms of information perception among modern students.

In gaining knowledge and professional competencies, students give priority to complex business games, case studies and brainstorming. These classes were highly appreciated in view of the fact that they develop a set of professional competencies, a systematic approach 
to the development of the profession is being formed. Teachers are more focused on creating content for distance learning, so the case study is highlighted.

Positive assessment of students and teachers received a practical lesson with a division into two opposing teams and a group of experts. On it students in a game form receive soft skills and hard skills. However, sometimes after the session, there is an element of conflict and discontent among the losers of the contest participants and group leaders, dissatisfaction with the assessment of experts.

\section{Conclusion}

The introduction of gaming in the university is controversial. With an understanding of the usefulness of gaming, only $29 \%$ of teachers constantly use gaming methods in class. The deterrent effect is influenced by such factors as a large amount of time to prepare for a lesson with gaming technology, a large training load and a lack of motivation for the teacher to use gaming methods in class. Students with a desire to participate in classes with gaming methods, as they are more deeply absorbed in the material, professional competencies are acquired, and the achievement of success in the class increases the social status of students. The most popular among them is the complex business game. However, the potential for gaming is not fully used.

To improve the effectiveness of the educational process, it is necessary:

1. Actively study and develop the theory and methodology of the gaming process of the educational process, participate in international conferences on gaming.

2. To improve the motivation of teachers and students to intensify the preparation, conduct and participation in classes using gaming methods.

3. To propagate the best practice of gaming of classes by conducting master classes, demonstration classes involving business partners and colleagues from other universities.

4. To introduce advanced gaming technologies into the educational process using electronic means, distance learning.

\section{Acknowledgements}

The publication was prepared with the financial support of the RFBR, project No. 17-0300059-ОГН. 


\section{References}

Alvarez, S., Nikendei, C., \& Schultz, J.-H. (2017). Development of a didactical training concept for peer tutors in gross anatomy. Anatomical sciences education, 10(5), 495502.

Baxter, R.J., Holderness, D.K., \& Wood, D.A. (2016). Applying basic gamification techniques to it compliance training: evidence from the lab and field. Journal of information systems. 30(3), 119-133. DOI: 10.2308/isys-51341.

Bartel, Alexander, Hagel, Georg, \& Wollf, Christian (2017). Effective integration of gamification and learning management systems for creating gamified learning arrangements. 3nd International Conference on Higher Education Advance. HEAd 17, Polytechnic University of Valencia, Valencia, Spain. http://dx.doi.org/10.4995/HEAd17.2017.5349.

Kirillov, A.V., Ushakov, D.S., Vinichenko, M.V., Makuchkin, S.A., \& Melnichuk, A.V. (2017). Career opportunities for the management's personnel reserve. Eurasian journal of analytical chemistry, 12(5b), 723-733.

Landers, R.N., \& Armstrong, M.B. (2017). Enhancing instructional outcomes with gamification: An empirical test of the technology-enhanced training effectiveness model. Computers in human behavior, 71, 499-507. DOI: 10.1016/j.chb.2015.07.031.

Lumsden, J., Edwards, E.A., Lawrence, N.S., Coyle, D., \& Munafo, M.R. (2016). Gamification of cognitive assessment and cognitive training: a systematic review of applications and efficacy. JMIR SERIOUS GAMES. 4(2), e11. DOI: 10.2196/games.5888.

Marti-Parreno, J., Segui-Mas, D., \& Segui-Mas, E. (2016). Teachers`attitude towards and actual use of gamification. 2nd International Conference on Higher Education Advance. HEAd 16, 21-23 June 2016, Valencia, Spain, Social and Behavioral Science, 228, 682688.

Martinetti, Alberto, Parada Puig Jorge Eduardo, Oude Alink, Charlotte, Thalen, Jos \& van Dongen, L.A.M. (2017). Gamification in teaching maintenance engineering: a Dutch experience in the rolling stock management leaning. 3nd International Conference on Higher Education Advance. HEAd 17, Polytechnic University of Valencia, Valencia, Spain. DOI: http://dx.doi.org/10.4995/HEAd17.2017.5332.

Miguel, S.E., Sorolla, G.R., Gato, M.E.P., \& Guillem, J.M.A. (2017). Gamification in business training. DIRECCION Y ORGANIZATION, 62, 35-40.

Moore, K.A., \& Pearson, B.J. (2017). Soft skills in an online class. Horttechnology, 27(5), 583-585. 
Rogach, O.V., Frolova, E.V., \& Ryabova, T. M. (2017). Academic Competition: Rating Race. European Journal of Contemporary Education, 6(2), 297-307. DOI: 10.13187/ejced.2017.2.297.

Sans, J. A., Manjón, F. J., Cuenca-Gotor, V., Giménez-Valentín, M. H., Salinas, I., Barreiro, J. J., Monsoriu, J. A. \& Gomez-Tejedor, J. A. (2015). Smartphone: a new device for teaching Physics. 1st International Conference on Higher Education Advances, HEAd'15. Polytechnic University of Valencia, Valencia, Spain. DOI: http://dx.doi.org/10.4995/HEAd15.2015.332.

Serrano, J. Javier \& Fajardo, Felix (2017). The ICT and gamification: tools for improving motivation and learning at universities. 3nd International Conference on Higher Education Advance. HEAd 17, Polytechnic University of Valencia, Valencia, Spain. DOI: http://dx.doi.org/10.4995/HEAd17. 2017. 5286.

Vinichenko, M.V.. Karácsony, P., Demcheko, T.S., Ilina, I.Y., \& Makuchkin, S.A. (2017). Improvement of youth personnel policy: Social inspection. Eurasian Journal of Analytical Chemistry, 7b(12), 1069-1077.

Wittenbaum, G.M., Hollingshead, A.B., Paulus, P.B., Hirokawa, R.Y., Ancona, D.G., Peterson, R.S., Jehn, K.A., \&Yoon, K. (2004). The functional perspective as a lens for understanding groups. Small Group Research, 35(1), 17-43.

Zdravkova, K. (2016). Reinforcing social media based learning, knowledge acquisition and learning evaluation. 2nd International Conference on Higher Education Advance. HEAd 16, 21-23 June 2016, Valencia, Spain, Social and Behavioral Science, 228, 1623. 